\title{
A study of chromosome association and chiasma formation in the amphidiploid between Lolium multiflorum and Festuca drymeja
}

\author{
W. G. MORGAN \& HUGH THOMAS \\ AFRC/IGER, Welsh Plant Breeding Station, Aberystwyth, Dyfed SY23 3EB, UK
}

\begin{abstract}
The chromosomes of Festuca drymeja are larger than those of Lolium multiflorum and the two complements can be distinguished in the $F_{1}$ hybrid and allotetraploid. Chromosome associations at metaphase 1 in the amphidiploid was typical of an allopolyploid because all the bivalents were symmetrical, which indicates complete preferential homologous chromosome pairing. Chromosome behaviour within the two genomes of the amphidiploid differed from that in the corresponding diploid species. The mean chiasmata per bivalent of the $F$. drymeja complement was much higher in the allotetraploid than in the diploid species and there was a corresponding reduction in the $L$. multiflorum complement compared with the diploid. Total chiasma frequency of the amphidiploid was determined by the additive effect of the two genomes but there is evidence that the distribution of chiasmata was related to the specific genomes.
\end{abstract}

Keywords: allotetraploid, chromosome association, Festuca drymeja, Lolium multiflorum.

\section{Introduction}

Quantitative changes in nuclear DNA amounts have been shown to be associated with the evolution of diploid species in Lolium and Festuca (Seal \& Rees 1982). All the diploid species have the same chromosome number $(n=7)$ and the variation in total DNA between species is distributed throughout the chromosomes of the complement. The diploid species $F$. drymeja and L. multiflorum have 7.17 and $4.31 \mathrm{pg}$ of nuclear DNA respectively and this is reflected in the size of the chromosome complements, the $F$. drymeja chromosomes being distinctly larger than those of $L$. multiflorum (Morgan \& Thomas, 1983). Due to the large differences in chromosome size between the two complements it is possible to distinguish them at meiosis in the allotetraploid combining the two species. This provides an opportunity to study the meiotic behaviour of the two sets of chromosomes in the allotetraploid condition compared to their behaviour as separate species.

\section{Materials and methods}

The source of the diploid species $F$. drymeja has previously been described by Morgan et al. (1979). Synthetic autotetraploid genotypes of $F$. drymeja and the L. multiflorum tetraploid cultivar Sabalan (WPBS) were used as parents to produce the allotetraploid. Crosses were made by emasculating inflorescences of L. multiflorum $(2 n=4 x=28)$ and using autotetraploid genotypes of $F$. drymeja $(2 n=4 x=28)$ as male pollen plants. Because the hybrid was difficult to obtain, embryo rescue was necessary to retrieve the allotetraploid. Immature embryos were removed 15-18 days after pollination and cultured on a modified Gamborg's B5 medium (Gamborg et al., 1968) with 3 per cent sucrose but without 2,4-D and kinetin.

Root-tips were pre-treated for somatic squash preparations in distilled water at $1-2^{\circ} \mathrm{C}$ for $16 \mathrm{~h}$, fixed in three parts alcohol to one part acetic acid, hydrolysed in $1 \mathrm{~N} \mathrm{HCl}$ at $60^{\circ} \mathrm{C}$ for $10 \mathrm{~min}$ and stained in 1.5 per cent acetocarmine. Immature inflorescences were fixed in 6:3:1 Carnoy's solution for meiotic analyses and anthers stained in alcoholic hydrochloric acidcarmine (Snow, 1963) for $2 \mathrm{~h}$ at $60^{\circ} \mathrm{C}$. The anthers were squashed in 45 per cent acetic acid. Chromosome associations and chiasma frequency were recorded in 25 pollen mother cells (PMCs) per plant.

\section{Results}

The difference in the size of the two complements is evident from Fig. 1a, the $F$. drymeja chromosomes 
being larger than those of $L$. multiflorum. Details of chiasma frequencies in the two species are presented in Table 1. Despite the larger size of the $F$. drymeja chromosomes the mean chiasmata per bivalent was significantly lower than in $L$. multiflorum $(P=<0.001)$. In $L$. multiflorum the majority of the bivalents were rings with two chiasmata frequency while rods with a single chiasma were most prevalent in $F$. drymeja. Only one accession of $F$. drymeja was available for study and it is not possible to reach any definite conclusions as to whether the low chiasma frequency is characteristic of the species or that this particular accession is unique. None of the other diploid Festuca species that have been studied had a comparable low chiasma frequency.

Chromosome association and chiasma frequencies were scored in five allotetraploid plants and the results are given in Table 2 . All the bivalents were symmetrical and clearly show that the observed meiotic behaviour at metaphase 1 was typical of an allopolyploid. Chromosome association was completely preferential in the allotetraploid and only associations between homozygous chromosomes were observed, i.e. homomorphic bivalents. In the corresponding diploid hybrid there was little evidence of homology between the chromosomes of the two species because only 0.65 bivalents were formed per cell between multiflorum and drymeja chromosomes (Thomas \& Morgan, 1990).

There was significant variation in total chiasma frequency between the five allotetraploid plants (Tables 2 and 3). One plant, P107/123/4, had a higher frequency of univalents than the other four with a corresponding reduction in mean chiasma frequency. The pooled value for mean chiasmata per plant for the two diploid species was 21.29 and three of the allotetraploids had mean chiasma frequencies close to this value. The presence of univalents in plant P107/123/4 resulted in a marked reduction in chiasma frequency while plant $\mathrm{P} 107 / 123 / 5$ had a higher chiasma frequency than the combined diploid value.

The overall mean chiasmata per cell in the amphidiploids (20.56) was lower than the combined value of the diploid species (21.30). However, there were significant differences between plants (Table 3 ) and in plant $P 107 / 123 / 5$, which had the most regular meiotic behaviour, the mean number of chiasmata formed was greater (24.44). In general the number of chiasmata formed in the amphiploid is determined by the additive effect of the constituent genomes.

An interesting feature of the meiotic behaviour of the amphidiploids is the difference in the distribution of chiasmata between the two complements compared with the corresponding diploid species. In the amphidiploids the mean chiasma frequency of the $F$. drymeja complement was greater than in the diploids and there was a consistent reduction in chiasma frequency in the L. multiflorum set. The greatest increase was recorded in plant P107/123/5 which had the highest total chiasma frequency with near complete bivalent pairing, some cells having the maximum 14 bivalents (Fig. 1b). The difference between the two genomes of the amphidiploid in the mean number of chiasmata per cell was significant (Table 3 ). In addition there was also a significant plant-genome interaction; $F$. drymeja had
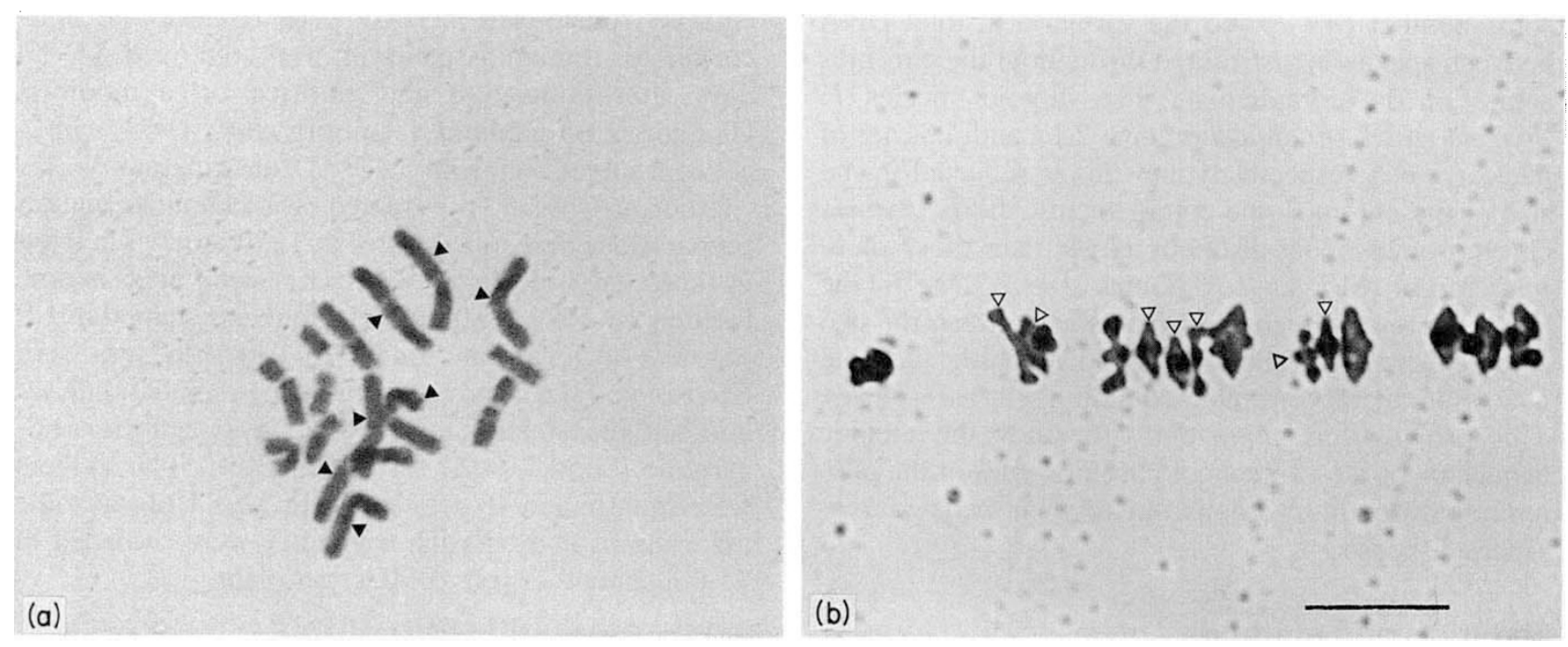

Fig. 1 (a) Metaphase plate of the $\mathrm{F}_{1}$ diploid hybrid $L$. multiflorum $\times F$. drymeja. The seven larger chromosomes form the $F$. drymeja complement (closed arrowhead). (b) First metaphase in meiosis in pollen mother cells in the amphidiploid $L$. multiflorum $\times F$. drymeja showing $7 \mathrm{II}$ dr.(large) $+7 \mathrm{II} \mathrm{Lm}$ (open arrowhead). Bar represents $10 \mu \mathrm{m}$. 
Table 1 Metaphase 1 chromosome associations in the diploid species $F$. drymeja and L. multiflorum

\begin{tabular}{|c|c|c|c|c|c|}
\hline \multirow[b]{2}{*}{ Species } & \multirow{2}{*}{$\begin{array}{l}\text { Plant } \\
\text { number }\end{array}$} & \multicolumn{2}{|c|}{ Frequency } & \multirow{2}{*}{$\begin{array}{l}\text { Chiasmata } \\
\text { per bivalent }\end{array}$} & \multirow{2}{*}{$\begin{array}{l}\text { Mean } \\
\text { chiasmata }\end{array}$} \\
\hline & & Rods & Rings & & \\
\hline \multirow{6}{*}{ L. multiflorum } & 1 & 2.18 & 4.82 & 1.717 & 12.02 \\
\hline & 2 & 2.46 & 4.52 & 1.734 & 12.10 \\
\hline & 3 & 1.94 & 5.06 & 1.794 & 12.56 \\
\hline & 4 & 1.50 & 5.50 & 1.859 & 13.02 \\
\hline & 5 & 1.64 & 5.36 & 1.888 & 13.22 \\
\hline & Mean & 1.944 & 5.052 & 1.798 & 12.584 \\
\hline \multirow[t]{6}{*}{ F. drymeja } & 1 & 5.52 & 1.44 & 1.226 & 8.58 \\
\hline & 2 & 5.48 & 1.50 & 1.241 & 8.66 \\
\hline & 3 & 4.90 & 2.06 & 1.312 & 9.18 \\
\hline & 4 & 5.44 & 1.52 & 1.247 & 8.73 \\
\hline & 5 & 5.28 & 1.64 & 1.248 & 8.64 \\
\hline & Mean & 5.32 & 1.632 & 1.255 & 8.75 \\
\hline
\end{tabular}

Table 2 Summary of chromosome association at metaphase 1 in the amphidiploid L. multiflorum $\times$ F. drymeja

\begin{tabular}{|c|c|c|c|c|c|c|c|}
\hline \multirow[b]{2}{*}{$\begin{array}{l}\text { Plant } \\
\text { number }\end{array}$} & \multicolumn{3}{|c|}{ L. multiflorum } & \multicolumn{3}{|l|}{ F. drymeja } & \multirow[b]{2}{*}{$\begin{array}{l}\text { Total } \\
\text { chiasmata } \\
\text { per cell }\end{array}$} \\
\hline & $\begin{array}{l}\text { Chiasmata } \\
\text { per bivalent } \\
\text { formed }\end{array}$ & $\begin{array}{l}\text { Number } \\
\text { of bivalents }\end{array}$ & $\begin{array}{l}\text { Mean } \\
\text { chiasmata } \\
\text { per cell }\end{array}$ & $\begin{array}{l}\text { Chiasmata } \\
\text { per bivalent } \\
\text { formed }\end{array}$ & $\begin{array}{l}\text { Number } \\
\text { of bivalents }\end{array}$ & $\begin{array}{l}\text { Mean } \\
\text { chiasmata } \\
\text { per cell }\end{array}$ & \\
\hline $\mathrm{P} 107 / 123 / 5$ & 1.623 & 6.68 & 10.84 & 1.954 & 6.96 & 13.60 & 24.44 \\
\hline $\mathrm{P} 107 / 117 / 3$ & 1.495 & 6.32 & 9.48 & 1.813 & 6.68 & 12.12 & 21.60 \\
\hline $\mathrm{P} 107 / 92 / 3$ & 1.740 & 6.08 & 10.64 & 1.514 & 6.00 & 9.64 & 20.28 \\
\hline P107/117/4 & 1.648 & 5.56 & 9.04 & 1.702 & 6.52 & 11.16 & 20.20 \\
\hline $\mathrm{P} 107 / 123 / 4$ & 1.652 & 5.20 & 8.40 & 1.449 & 5.48 & 7.88 & 16.28 \\
\hline Mean & 1.632 & & 9.68 & 1.702 & & 10.88 & 20.56 \\
\hline
\end{tabular}

more chiasmata per bivalent in the plant with the highest total chiasmata compared with the plant with the lowest total chiasmata where the value for the $L$. multiflorum genome was greater (Table 2).

Further information on the differential response of the two sets of chromosomes is obtained by examining the relationship between the mean chiasmata per genome and total chiasmata. The mean chiasmata for $F$. drymeja and $L$. multiflorum genomes are plotted against chiasmata per cell in Fig. 2. The regression for $F$. drymeja and L. multiflorum was highly significant $(P=<0.001)$. Joint regression analysis confirmed that the two regressions were significantly different $(P=<0.001)$. The primary requirement in the distribution of chiasmata is the formation of the maximum number of associations that will result in normal disjunction of paired chromosomes at meiosis. Once this condition is satisfied, further chiasmata above this requirement would become distributed amongst the associated chromosomes. In the amphidiploid plants the opportunity is created for competition between the two genomes for the chiasmata available. The potential of $L$. multiflorum to achieve a significantly higher number of chiasmata per bivalent than $F$. drymeja is not realized in the amphidiploid. Although $L$. multiflorum had an advantage in mean chiasmata per bivalent at the low chiasmata value, the response of the $F$. drymeja complement to increasing total chiasmata was greater as shown in the slope of the two regression lines (Fig. 2). There is distinct evidence that the two complements behave differently in the hybrid and parental backgrounds.

The low chiasma frequency in the diploid $F$. drymeja genome is obviously due to a restriction on the number of chiasmata available and not to any anomaly in the mechanics of chromosome pairing because in the amphidiploid plants, chromosomes of $F$. drymeja can form higher numbers of chiasmata. The increase in 
Table 3 Analyses of variance of chromosome association and chiasma frequency in the amphidiploid $L$. multiflorum $\times F$. drymeja

\begin{tabular}{lrcc}
\hline & \multicolumn{3}{c}{ Mean square } \\
\cline { 2 - 4 } & \multicolumn{2}{c}{$\begin{array}{c}\text { Numbert } \\
\text { of bivalents }\end{array}$} & $\begin{array}{c}\text { Chiasmata } \\
\text { per cell }\end{array}$ \\
& d.f. & \\
\hline Analysis of all plants: & & & \\
Between genomes & 1 & $82192^{* * *}$ & $90.0^{* * *}$ \\
Between plants & 4 & $152641^{* * *}$ & $108.320^{* * *}$ \\
Genome/plant interaction & 4 & $24012^{* * *}$ & $41.100^{* * *}$ \\
Error & 240 & 6785 & 4.303 \\
Analysis not including plant P107/117/4: & \\
Between genomes & 1 & 20140 & $47.045^{* * * *}$ \\
Between plants & 3 & $200479^{* * *}$ & $143.752^{* * *}$ \\
Genome/plant interaction & 3 & 10162 & $50.392^{* * *}$ \\
$\quad$ Error & 192 & 6614 & 4.075 \\
\hline
\end{tabular}

*** $P \leqslant 0.001$.

$\dagger$ Cube transformation.

mean chiasmata per bivalent in the $F$. drymeja is achieved through a higher frequency of ring bivalents arising from the formation of a chiasma in both arms of the chromosomes which was only rarely achieved in the diploid.

Of the five amphidiploid plants studied, only in plant P107/123/5 were all the chromosomes associated at metaphase 1 as all the other plants showed some degree of univalence. Plant P107/123/4 had the least number of chromosomes associated with a mean of only 10.68 bivalents and a much reduced chiasma frequency. Analysis of variance of the number of bivalents in the five amphidiploid plants showed that the differences between plants and between genomes and the plant-genome interaction were significant (Table 3). From the data in Table 2 it is clear that this was mainly due to plant $\mathrm{P} 107 / 117 / 4$ where there was a distinct difference between the two genomes but the other four plants had a more even distribution of univalents amongst both complements. When the analysis of variance was repeated deleting the data for this plant only, the difference between plants was significant (Table 3). Failure of chromosome association could not be attributed to differences in homology but could be due to genotypic differences as nearly complete chromosome association was observed in plant P107/123/5. Genotypic interaction has been shown to lead to variable degrees of univalence in a range of diploid hybrids which had $F$. drymeja as one of the parents (Morgan et al., 1979). If partial univalence in the amphidiploids is due to a similar interaction the

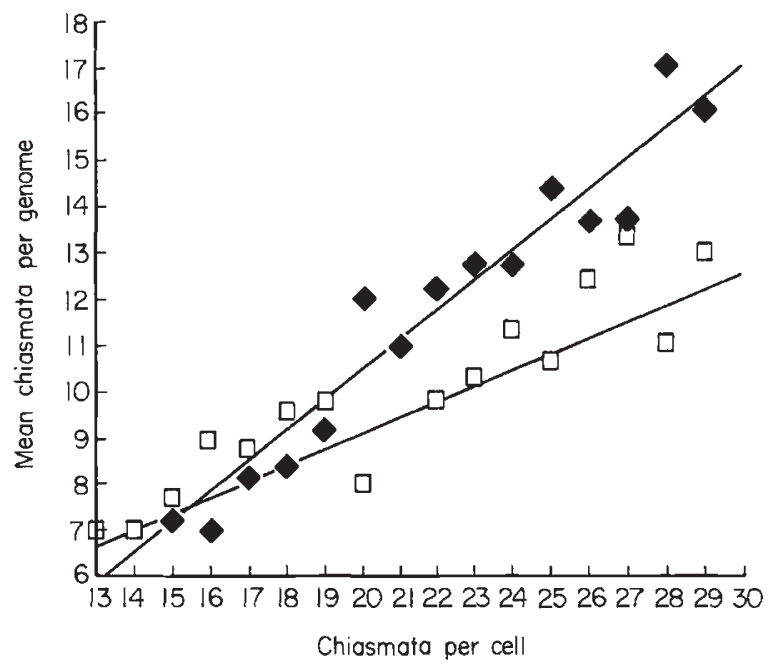

Fig. 2 The relationship between mean chiasmata per genome in the two genomes and chiasmata per cell of the amphidiploid. () L. multiflorum, (•) F. drymeja.

control system generally does not lead to a differential response from the two complements.

\section{Discussion}

The ability to identify the two chromosome complements in the amphidiploids has shown that chromosome association is typical of an allopolyploid. The nearly complete bivalent pairing and symmetry of the bivalents in P107/123/5 is clear proof that chromosome association at metaphase 1 is preferential. Such meiotic behaviour could have been predicted from the low frequency of chromosome associations observed in the $F_{1}$ hybrid (Morgan \& Thomas, 1983; Morgan, 1990). Although the initial alignment of the chromosomes probably depends on structural differences between the complements the frequency and distribution of chiasmata are also subject to the action and interaction of the two genomes present in the amphidiploid. The differences in size between the two chromosome sets allow their specific response to this control to be studied.

The distinct genomes responded differently to the control of chiasma frequency and distribution imposed by the amphidiploid genotype compared with their behaviour as diploid species. There was an interaction between the complements and genetic background in their response to the control of chiasmata frequency. $F$. drymeja with its larger size chromosomes was more effective in acquiring extra chiasmata under the control of the amphidiploid genotype than L. multiflorum chromosomes. The distribution of the available chiasmata in the amphiploid was different from that 
expected on the basis of the meiotic behaviour of the paternal diploid species. A similar pattern has been described by White \& Rees (1985) in an amphidiploid between Petunia parodii and $P$. parviflora where the complements were affected differently by control exercised by the hybrid genotype. In an amphidiploid genotype Allium fistulosum $\times A$. cepa the integrity of the diploid genomes was conserved because the characteristic proximal location of chiasmata in $A$. fistulosum and the terminal chiasmata in $A$. cepa were maintained in the amphidiploid combining both sets (Jones \& Clarke, 1942). The differential reaction of the Lolium and Festuca complements to the control system that operates for the distribution of chiasmata to bivalents agrees with previous observations on amphidiploids and reports of chromosome-specific control in asynaptic genotypes by Parker (1975) and Tease \& Jones (1976).

With the exception of plant P107/117/4, univalents were observed to occur throughout the two sets of chromosomes in the amphidiploids and there was no evidence of an interaction between the complements and the amphidiploid genotype in the occurrence of univalents. The nature of the control of univalence is unclear and the sterility of the amphidiploids precludes the conduct of any breeding experiments to investigate this any further. In studies of diploid trispecific hybrids, including $F$. drymeja as one of the parental species, variable failure of chromosome pairing was shown to be due to genotypic interactions (Morgan et al., 1979). If the univalence in the amphidiploids is an expression of similar genotypic interaction its effect is exercised over the whole genotype in contrast to the differential response of the two genomes in the distribution of chiasma. The control of the meiotic process is complex and hierarchical as proposed by Tease \& Jones (1976) with genes acting at different levels of organization.

In spite of the regular meiotic behaviour in the amphidiploid P107/123/5 it was completely sterile; no functional pollen was produced and no seeds were set in backcrosses to the tetraploid L. multiflorum. Although the combination of the two genomes in a single genotype gave rise to a vigorous hybrid with regular meiosis, genetic incompatibility between the genomes is expressed in the sterility of the amphidiploid.

\section{References}

GAMBORG, O. L., MiLler, R. A. AND OJMA, K. 1968. Nutrient requirements of suspension cultures of soyabean root cells. Exp. Cell. Res., 50, 151-158.

JONES, H. A. AND ClARKE, A. E. 1942. A natural amphidiploid from an onion species hybrid. Allium cepa $\times$ A. fistulosum. J. Hered., 33, 25-32.

MORGAN, w. G. 1990. Cytogenetic studies in triploid and amphidiploids involving Lolium and diploid Festuca species. Genome, 33, 472-477.

MORGAN, w. G. AND thOMAS, H. 1983. Hybrids between $L$. multiflorum and $F$. drymeja. In: Annual Report of the Welsh Plant Breeding Station for 1983, p. 116.

MORGAN, W. G., THOMAS, H. AND KIRBY, M. 1979. A study of chromosome association in hybrids between diploid species of Festuca. Chromosoma (Berl.), 75, 117-127.

PARKER, J. S. 1975. Chromosome-specific control of chiasma formation. Chromosoma, 49, 391-406.

SEAL, A. AND REES, H. 1982. The distribution of quantitative DNA changes associated with the evolution of Festuceae. Heredity, 49, 179-190.

sNOw, R. 1963. Alcoholic hydrochloric acid-carmine as a stain for chromosomes in squash preparations. Stain Technol., 38, 9-13.

TEASE, C. AND JONES, G. H. 1976. Chromosome-specific control of chiasma formation in Crepis capillaris. Chromosoma, 57, 33-49.

THOMAS, H. M. AND MORGAN, W. G. 1990. Analysis of synaptonemal complexes and chromosome pairing at metaphase 1 in the diploid inter-generic hybrid Lolium multiflorum $\times$ Festuca drymeja. Genome, 33, 465-471.

WHITE, J. AND REES, H. 1985. The chromosome cytology of a somatic hybrid petunia. Heredity, 55, 53-59. 